Niğde Ömer Halisdemir Üniversitesi Mühendislik Bilimleri Dergisi
Niğde Ömer Halisdemir University Journal of Engineering Sciences

\title{
Berilyum bakır alaşımında akımsız Ni-P ve Ni-B kaplamaların aşınma performansı
}

\section{Wear performance of electroless Ni-P and Ni-B coatings on beryllium copper alloy}

\author{
Ferda Mindivan 1 (D), Harun Mindivan ${ }^{2,}$ * [D \\ ${ }^{\prime}$ Bilecik Şeyh Edebali Üniversitesi, Biyomühendislik Bölümü, 11210, Bilecik, Türkiye \\ ${ }^{2}$ Bilecik Şeyh Edebali Üniversitesi, Makine Mühendisliği Bölümü, 11210, Bilecik, Türkiye
}

$\ddot{O} \mathbf{z}$

Berilyum bakır (Be-Cu) alaşımları yüksek sıcaklık iletkenliği ve nispeten yüksek mukavemetleri ile hızlı kalıp üretimi için uygun malzemelerdir. Ancak, düşük aşınma ve oksidayon direnci özellikleri nedeniyle kullanımları sınırlı kalmıştır. Bu çalışmada $\mathrm{Be}-\mathrm{Cu}$ alaşımı üzerine akımsız Nikel-Fosfor (Ni-P) ve Nikel-Bor (Ni-B) kaplamalar hazırlanmış ve aşınma özellikleri kaplanmamış alaşım ile karşılaştırılmıştır. Kaplamaların mikroyapı görüntüleri Ni$\mathrm{P}$ kaplamanın yaklaşık $12 \mu \mathrm{m}$ kalınlığında, düz bir yüzey sergilediği göstermiştir. Ni-B kaplamanın ise yaklaşık 7-8 $\mu \mathrm{m}$ ortalama kalınlıkta, pürüzlü ve dalgalı bir yüzey görüntüsüne sahip olduğu belirlenmiştir. XRD analiz sonuçları ile akımsız kaplamaların amorf ve kristalin bölgelerin karışımından ibaret olduğu ve Ni-B kaplamanın Ni-P kaplamaya kıyasla daha amorf yapı sergilediği tespit edilmiştir. Akımsız Ni-P ve Ni-B kaplamaların sertlik değerleri kaplanmamış alaşıma nazaran sırasıyla 2.2 ve 3.7 kat artmıştır. Akımsız Ni-B kaplamanın sertliğindeki artışa bağlı olarak, her iki yük altında (5 and $7.5 \mathrm{~N})$ aşınma kaybında \% 77 oranında azalma olduğu belirlenmiștir.

Anahtar kelimeler: Berilyum bakır alaşımı, Akımsız Ni-P kaplama, Akımsız Ni-B kaplama, Kuru aşınma

\section{Giris}

Moldmax HH, plastik enjeksiyon kalıp uygulamalarında soğutma performansını arttırmak amacıyla kullanılan bir BeCu kalıp alaşımıdır [1]. Düşük aşınma direnci ve oksidasyon $\mathrm{Be}-\mathrm{Cu}$ alaşımlarının kullanımını sınırlayan en önemli etkenlerdir [2]. Çeşitli kaplamalar arasında düşük aşınma hızı ve korozyon direnci gibi mükemmel fonksiyonel özelliklerinden dolayı sert krom (Cr) kaplama tercih edilmektedir. Ancak, altı değerlikli krom Cr (VI) içeren elektrolitlerin kullanımı ciddi çevre ve sağlık sorunları nedeniyle günümüzde kısıtlanmıştır. $\mathrm{Bu}$ kısıtlamalar Avrupa'da REACH (Kimyasalları Kayd, Değerlendirilmesi, Yetkilendirilmesi ve Kısıtlanması), ABD'de EPA (Çevre Koruma Ajansı) ve OSHA (İş Güvenliği ve Sağllk İdaresi) tarafindan düzenlenmektedir. Doğası gereği kanserojen ve cilt tahrişine neden olan $\mathrm{Cr}(\mathrm{VI})$

\begin{abstract}
Beryllium copper (Be-Cu) alloys are suitable materials for mold production speedy (rapid mold production) with their high temperature conductivity and relatively high strength. However, their use has been limited due to their low wear and oxidation resistance properties. In this study, electroless Nickel-Phosphorus (Ni-P) and Nickel-Boron (Ni-B) coatings were prepared on the Be-Cu alloy and the wear properties were compared with the uncoated alloy. Microstructure images of the coatings showed that the Ni$P$ coating exhibited a flat surface with a thickness of about $12 \mu \mathrm{m}$. Ni-B coating had a rough and wavy surface with an average thickness of approximately 7-8 $\mu \mathrm{m}$. It was determined that the electroless coatings consisted of a mixture of amorphous and crystalline regions with the XRD analysis results and the Ni-B coating exhibited more amorphous structure compared to the Ni-P coating. The hardness values of electroless $\mathrm{Ni}-\mathrm{P}$ and $\mathrm{Ni}-\mathrm{B}$ coatings increased by 2.2 and 3.7 times, respectively, compared to the uncoated alloy. Depending on the increase in the hardness of the electroless Ni-B coating, it was determined that there was a $77 \%$ reduction in wear loss under both loads (5 and $7.5 \mathrm{~N})$.
\end{abstract}

Keywords: Beryllium copper alloy, Electroless Ni-P coating, Electroless Ni-B coating, Dry wear

kaplama sırasında açığa çıkan gaz, akciğer sorunlarına da neden olmaktadır. Solunum cihazı kullanımı ve egzoz sistemlerinin çalıştırılması gibi güvenlik önlemleriyle toksik $\mathrm{Cr}$ (VI) kalıntı elektrolitin bertaraf edilmesi masraflıdır. Ayrıca sert krom kaplamaların performansı, mikroçatlaklara ve kaplama sırasında gelişen kalıntı çekme gerilmelerine de bağlıdır. Sert krom kaplamalar, kristal yapıdaki değişiklikler nedeniyle üretim sırasında sürünmeye uğrayarak ya mikroçatlaklara ya da kalıntı çekme gerilmelere sahip kaplamaların oluşmasına yol açmaktadırlar. Çatlaklar tipik olarak yaklaşık $2 \mu \mathrm{m}$ derinliğe sahiptir, ancak çatlaklar bir araya gelerek farklı derinlik, boyut ve yoğunlukta desenler oluşturabilirler. Diğer taraftan, kaplama sırasında oluşan bu mikroçatlaklar, sert krom kaplamanın aşınma ve korozyon direncini olumsuz yönde etkileyebilmektedir [3]. Sonuç olarak, krom kaplamayla karşılaştırılabilir ve hatta daha

\footnotetext{
* Sorumlu yazar / Corresponding author, e-posta / e-mail: hmindivan@gmail.com (H. Mindivan)

Geliş / Recieved: 17.11.2021 Kabul / Accepted: 21.01.2022 Yayımlanma/Published: 15.04.2022

doi: 10.28948/ngmuh.1024914
} 
üstün fonksiyonel özellikler sergileyen ancak ciddi sağlık sorunu riski olmayan alternatif kaplamalar üzerine literatürde pek çok çalışma yapılmıştır [4]. Akımsız nikel kaplamalar, üniform kaplama kalınlığı, yüksek sertlik, aşınma ve korozyon direnci, lehimlenebilirlik ve kaynak kabiliyeti, yağlayıcılık gibi özelliklerinden dolayı elektronik, bilgisayar, otomotiv, uçak-uzay, kimya, plastik, optik, vb. birçok alanda kullanım olanağı sunmaktadır. Akımsız kaplama çeşitlerinden Ni-P ve Ni-B kaplamalar en bilinenler arasındadırlar. Hipofosfit kullanılarak akımsız nikeli indirgemek yaygın olarak bilinse de, yakın zamanda borohidrit ile indirgeme işlemi de kullanılmaya başlamıştır. Bunun sebebi ise diğer indirgen maddelerle kıyaslandığında borohidrit iyonu en güçlü indirgen olması ve borohidritin indirgediği akımsız nikel kaplamaların sertlik ve aşınma direncinin daha yüksek olmasıdır.

$\mathrm{Bu}$ çalışmada $\mathrm{Be}-\mathrm{Cu}$ alaşımı yüzeyine $\mathrm{Ni}-\mathrm{P}$ ve $\mathrm{Ni}-\mathrm{B}$ akımsız kaplamalar yapılarak sertlik ve aşınma gibi yüzey özellikleri incelenerek, kaplanmamış $\mathrm{Be}-\mathrm{Cu}$ alaşımı ile karşılaştırılmıştır.

\section{Materyal ve metot}

Akımsız kaplama işlemleri için altlık malzeme olarak Moldmax HH Be-Cu alaşımı (20 x 10 x 5 mm) kullanılmıştır. $\mathrm{Bu}$ altlık malzemenin kimyasal bileşimi ağırlıkça (ăg.) \% değerleri şeklinde Tablo 1'de verilmiştir.

Tablo 1. Be-Cu alaşımının kimyasal bileşimi

\begin{tabular}{llll}
\hline Element & $\mathrm{Be}$ & $\mathrm{Co}+\mathrm{Ni}$ & $\mathrm{Cu}$ \\
A ̆. $\%$ & 1.9 & 0.25 & Kalan \\
\hline
\end{tabular}

Be-Cu alaşım örnekleri, silisyum karbür ( $\mathrm{SiC}$ ) zımparalar kullanilarak sirasiyla 240, 400, 600, 800, 1000 ve 1200 numaralı zımpara kağıtları ile ıslak zımparalanmış, daha sonra örneklerin yüzeyleri alkolle temizlenerek 1 mikron Alümina $\left(\mathrm{Al}_{2} \mathrm{O}_{3}\right)$ solüsyonu ile parlatılarak kaplama işlemine hazır hale getirilmiştir.

Kaplama tabakasının homojen ve düz olması arzu edildiğinden altlık malzemeye bazı ön işlemler uygulamak gerektiğinden, kaplama öncesi Be-Cu levhalar ağ. \%10 KOH alkali temizleyici içerisinde $5 \mathrm{dk}$. boyunca $60^{\circ} \mathrm{C}$ ' de tutulmuştur. Ardından kaplamaya hazır aktif bir yüzey elde etmek için $30 \mathrm{~s}$ boyunca hacimce $\% 10 \mathrm{H}_{2} \mathrm{SO}_{4}$ çözeltisinde bekletilip [5], saf su ile y1kanarak kaplama banyosuna yerleştirilmiştir.

Daha önce AISI 316L paslanmaz çelik üzerine Ni-P, Ni$\mathrm{B}$ ve Ni-P/Ni-B dubleks [6], AA7075 alüminyum alaşımı üzerine Ni-P/Ni-B dubleks [7] ve saf Ti üzerine Ni-B [8] çalışmalarında optimize edilmiş kaplama koşulları bu çalışmada kullanılan hem Ni-P hem de Ni-B kaplama banyolarını oluşturmak için kullanılmıştır. $5 \mathrm{~g} / \mathrm{L}$ nikel, 40 g/L sodyum hipofosfit $\left(\mathrm{NaH}_{2} \mathrm{PO}_{2}\right)$ içeren ticari bir çözelti (DURNI-COAT DNC 520-9) kullanılarak akımsız Ni-P kaplama banyosu hazırlanmıştır. Akımsız Ni-B kaplamanın banyo bileşimi ve kaplama parametreleri ise Tablo 2'de verilmiştir. Nikel kaynağı olarak nikel klorür hekzahidrat $\left(\mathrm{NiCl}_{2} \cdot 6 \mathrm{H}_{2} \mathrm{O}\right)$, indirgeme elemanı olarak sodyum bor hidrür $\left(\mathrm{NaBH}_{4}\right)$, kompleksleştirici etilen diamin $\left(\mathrm{C}_{2} \mathrm{H}_{8} \mathrm{~N}_{2}\right)$, çözelti pH' sını ayarlamak için sodyum hidroksit $(\mathrm{NaOH})$ ve çözeltinin kararlılığını sağlamak için talyum asetat $\left(\mathrm{CH}_{3} \mathrm{COOTI}\right)$ kullanılmıştır. $250 \mathrm{ml}$ ' lik bir beherde, yağ banyosu içerisinde bulunan akımsız Ni-P ve Ni-B kaplama banyo karışımlarının çalışma koşulları Tablo 3'de verilmiştir. Kaplamalar manyetik karıştırıcı üzerinde, 250 dev/dk. karıştırma hızında, $60 \mathrm{dk}$. süreyle, $5 \mathrm{~mm}$ çapında ve $2 \mathrm{~cm}$ uzunluğunda bir politetrafloroetilen (PTFE) esaslı manyetik bir balık yardımıyla gerçekleştirilmiştir.

Tablo 2. Akımsız Ni-B kaplama banyosu bileşenleri

\begin{tabular}{cc}
\hline $\mathrm{NaBH}_{4}$ & $1 \mathrm{~g} / \mathrm{l}$ \\
$\mathrm{NiCl}_{2} \cdot 6 \mathrm{H}_{2} \mathrm{O}$ & $30 \mathrm{~g} / \mathrm{l}$ \\
$\mathrm{C}_{2} \mathrm{H}_{8} \mathrm{~N}_{2}$ & $90 \mathrm{ml} / 1$ \\
$\mathrm{NaOH}$ & $90 \mathrm{~g} / \mathrm{l}$ \\
$\mathrm{CH}_{3} \mathrm{COOTl}$ & $18 \mathrm{mg} / 1$ \\
\hline
\end{tabular}

Tablo 3. Akımsız Ni-P ve Ni-B kaplama koşulları

\begin{tabular}{lll}
\hline & Ni-P & Ni-B \\
\hline Sicaklık & $90^{\circ} \mathrm{C}$ & $95^{\circ} \mathrm{C}$ \\
$\mathrm{pH}$ & 4.6 & 14 \\
Süre & $60 \mathrm{dk}$. & $60 \mathrm{dk}$. \\
Karıştırma Hızı & $250 \mathrm{dev} / \mathrm{dk}$. & $250 \mathrm{dev} / \mathrm{dk}$. \\
\hline
\end{tabular}

Kaplamaların mikroyapısı Nikon marka Eclipse LV150 model optik metal mikroskobu (OM) kullanılarak incelenmiştir. Kaplamaların faz analizleri Panalitical X-ışını kırınım ölçer (XRD) kullanılarak gerçekleştirilmiştir. XRD ölçümlerinde $\lambda=1.54059 \AA$ dalga boyuna sahip $\mathrm{CuK}_{\alpha} 1$ şınımı kullanılmıştır. Akımsız Ni-P ve Ni-B ile kaplanan örneklerin sertlik testleri, yüzeylere dik yönde kesit buyunca kesilip metalografik işlemlerle hazırlandıktan sonra Shimadzu HVM mikrosertlik cihazında Vickers batıcı uç kullanılarak $10 \mathrm{~g}$ yük altında yapılmıştır.

Bu çalışmada Be-Cu alaşımı, Ni-P ve Ni-B kaplamaların oda sıcaklığında doğrusal zit yönlü düzlem-bilye aşınma (reciprocating ball-on-flat) cihazında aşınma deneyleri yapılıp, sürtünme katsayıları belirlenmiştir. Aşınma deneyleri iki farklı normal yükte $(5$ ve $7.5 \mathrm{~N}), 1,9 \mathrm{~cm} / \mathrm{s}$ hızda, $10 \mathrm{~mm}$ çapında alümina $\left(\mathrm{Al}_{2} \mathrm{O}_{3}\right)$ bilye ile yapıllmıştır. Toplam aşınma mesafesi 57.5 m'dir. Deneyler sırasında ortamın bağıl nem değeri \%30’ dur. Aşınma deneyleri öncesi numunelerin yüzeyleri ve deneyde kullanılan bilyeler alkol ile temizlenmiştir. Aşınma deneyleri sonrasında aşınma izlerinin 2 boyutlu profilleri Mitutoyo Surtest SJ-400 profilometre cihazı ile 3 boyutlu profilleri ise Nikon görüntüleme yazılımı NIS-Elements ile elde edilmiştir. Ayrıca kaplamaların yüzey pürüzlülüğü de 2 boyutlu profil cihaz ile ölçülmüştür. Profillerden elde edilen $\mathrm{R}_{\mathrm{a}}$ : aritmetik ortalama pürüzlülük değerini, $\mathrm{R}_{\mathrm{y}}$ : değerlendirme uzunluğundaki en yüksek tepe-çukur parametresini, $\mathrm{R}_{\mathrm{z}}$ : ortalama maksimum yüksekliği, $\mathrm{R}_{\mathrm{q}}$ : aritmetik ortalama sapmaların karekökünü temsil etmektedir.

\section{Bulgular ve tartışma}

Akımsız Ni-P ve Ni-B kaplamaların enine kesit ve yüzey OM görüntüleri ve yüzey pürüzlülük değerleri sırasıyla Şekil 1ve Şekil 2'de verilmiştir. Ni-P kaplama, yaklaşık $12 \mu \mathrm{m}$ kalınlığa sahip düz bir yüzey sergilerken, Ni-B kaplama ise yaklaşık 7-8 $\mu \mathrm{m}$ ortalama kalınlığa sahip olup pürüzlü ve dalgalı bir yüzey görüntüsü sunmuştur (Şekil 1). Akımsız Ni- 
P kaplamanın yüksek yoğunluklu, gözeneksiz ve pürüzsüz yüzey görüntüsü (Şekil 1a ve Şekil 2) literatürde verilen akımsız Ni-P kaplamaların yüzey görüntüleri ile uyumludur [9]. Akımsız Ni-B kaplama ise karnabaharımsı birçok küresel tanenin sık, kompakt ve pürüzlü yüzey görüntüsü (Şekil 1b ve Şekil 2) daha önce yapılan çalışmalarla tutarlı olduğu belirlenmiştir [10]. Akımsız Ni-B kaplamada indirgeyici olarak borhidrür $\left(\mathrm{BH}_{4}^{-}\right)$kullanılmıştır. Borhidrür aşağıda Denklem (1) ve Denklem (2)' de gösterildiği gibi iki yolla oksitlenir, Denklem (3)' de ise nikel metalinin oluşumu gösterilmektedir.

$$
\begin{gathered}
\mathrm{BH}_{4}{ }^{-}+4 \mathrm{OH}^{-} \rightarrow \mathrm{BO}_{2}^{-}+2 \mathrm{H}_{2} \mathrm{O}+2 \mathrm{H}_{2}(\mathrm{~g})+4 \mathrm{e}^{-} \\
\mathrm{BH}_{4}^{-} \rightarrow \mathrm{B}+2 \mathrm{H}_{2}(\mathrm{~g})+\mathrm{e}^{-} \\
\mathrm{Ni}^{2+}+2 \mathrm{e}^{-} \rightarrow \mathrm{Ni}
\end{gathered}
$$

Denklem (1)'e göre, borhidrürden dört elektron açığa çıkar. Elektronları alarak, nikel iyonları indirgenerek nikel metali oluşur (Denklem (3)). Bor atomları Denklem (2)'ye göre birikmektedir. Sonuç olarak, altlık üzerinde Ni-B alaşımı oluşmaktadır [5].

Akımsız nikel kaplama çözeltilerinde hipofosfit kullanılarak meydana gelen kimyasal reaksiyonlar için de çeşitli mekanizmalar önerilmiștir. En yaygın olarak kabul edilen mekanizmalar aşağıdaki denklemlerle gösterilmiştir [11].

- Hipofosfitin yüzeyde meydana gelen katalitik oksidasyonu ile nikel ve hidrojen iyonlarının indirgendiği elektrokimyasal mekanizma aşağıda Denklem (4), (5), (6) ve (7) ile gösterilmiştir:

$$
\begin{gathered}
\mathrm{H}_{2} \mathrm{PO}_{2}^{-}+\mathrm{H}_{2} \mathrm{O} \rightarrow \mathrm{H}_{2} \mathrm{PO}_{3}^{-}+2 \mathrm{H}^{+}+2 \mathrm{e}^{-} \\
\mathrm{Ni}^{+2}+2 \mathrm{e}^{-} \rightarrow \mathrm{Ni} \\
2 \mathrm{H}^{+}+2 \mathrm{e}^{-} \rightarrow \mathrm{H}_{2} \\
\mathrm{H}_{2} \mathrm{PO}_{2}^{-}+2 \mathrm{H}^{+}+\mathrm{e}^{-} \rightarrow \mathrm{P}+2 \mathrm{H}_{2} \mathrm{O}
\end{gathered}
$$

- Yüzeyde adsorbe edilen hipofosfit molekülünün katalitik dehidrojenasyonu sonucu atomik hidrojenin açığa çıktığı atomik hidrojen mekanizması aşağıda Denklem (8), (9) ve (10) ile gösterilmiştir. Adsorplanan aktif hidrojen daha sonra yüzeydeki nikeli indirgemektedir (Denklem (9)). Aynı zamanda, adsorplanan hidrojenin bir kısmı, katalitik yüzeydeki hipofosfitin küçük bir miktarını suya, hidroksil iyonuna ve fosfora indirgemektedir (Denklem (10)).

$$
\begin{gathered}
\mathrm{H}_{2} \mathrm{PO}_{2}{ }^{-}+\mathrm{H}_{2} \mathrm{O} \rightarrow \mathrm{HPO}_{3}{ }^{-2}+\mathrm{H}^{+}+2 \mathrm{H}_{\mathrm{ads}} \\
2 \mathrm{H}_{\mathrm{ads}}+\mathrm{Ni}^{+2} \rightarrow \mathrm{Ni}+2 \mathrm{H}^{+}
\end{gathered}
$$

$$
\mathrm{H}_{2} \mathrm{PO}_{2}+\mathrm{H}_{\mathrm{ads}} \rightarrow \mathrm{H}_{2} \mathrm{O}+\mathrm{OH}^{-}+\mathrm{P}
$$
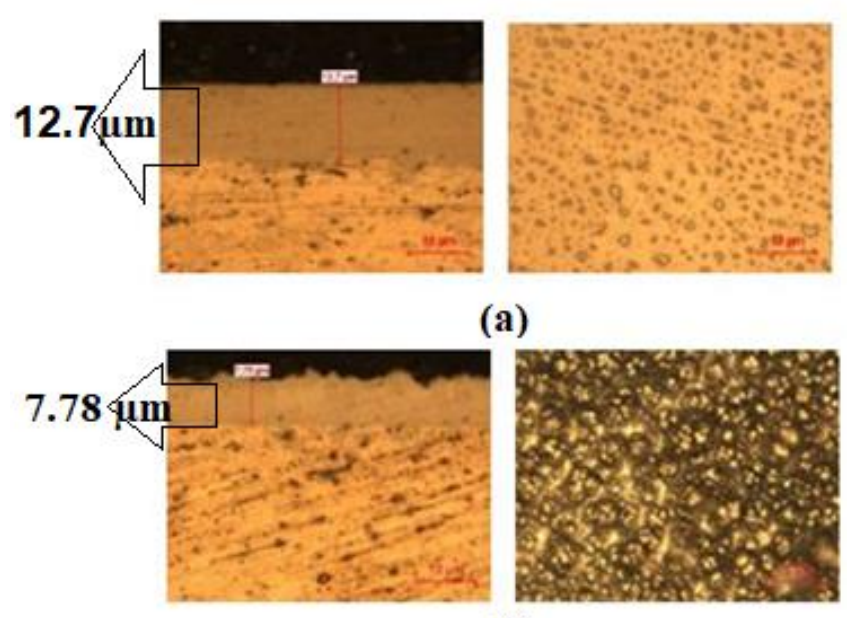

(b)

Şekil 1. Akımsız (a) Ni-P ve (b) Ni-B kaplamaların kesit ve yüzey $\mathrm{OM}$ görüntüleri

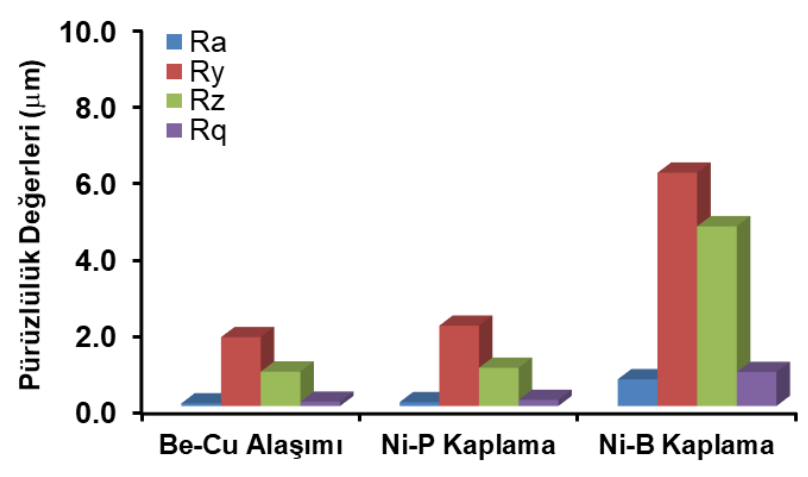

Şekil 2. Be-Cu alaşımı, akımsız Ni-P ve Ni-B kaplamaların yüzey pürüzlülük değerleri ve yüzey topografyaları

Akımsız Ni-P ve Ni-B kaplamaların ve karşılaştırma yapılacak olan Be-Cu alaşımının XRD paternleri Şekil 3'de verilmiştir. Şekil 3'de $2 \theta^{\circ}=42,99^{\prime}$ de $\mathrm{Cu}(111), 2 \theta^{\circ}=50,00^{\prime}$ de $\mathrm{Cu}(200)$ ve $2 \theta^{\circ}=73,26^{\prime}$ de $\mathrm{Cu}$ (220) düzlemlerine ait kristal pikleri görülmektedir. Be-Cu alaşıma ait Şekil 3'de verilen düzlem pikleri daha önce literatürde verilen $\mathrm{Be}-\mathrm{Cu}$ alaşımının kristal pikleri ile uyumludur [12]. Akımsız kaplamaların XRD paternlerinde ise kristal yapının izlerini sunan piklerin varlığı ile beraber kısmen genişlemiş yani amorf yapının da mevcudiyetini gösteren piklerin varlığ açıkça görülmüştür. Dolayısıyla bu çalışmada elde edilen 
akımsız kaplamaların hem amorf hem de kristal bölgelere sahip olduğu anlaşılmaktadır. Bu sonuç, daha önce farklı altlık malzemeler üzerine yapılan çalışmalarla da rapor edilmiştir [13, 14]. Bunun yanında, bazı çalışmalarda kaplamaların XRD paternlerinde geniş bir pik ile yalnızca amorf yapının varlığı belirlenmiştir $[15,16]$. Bu çalışmada da akımsız Ni-B kaplamada kısmi genişlemiş bölgede kristalin piklerden biri kaybolmaktadır ve bu yüzden Ni-B kaplama Ni-P kaplamaya göre daha amorf yap1 sergilemektedir.

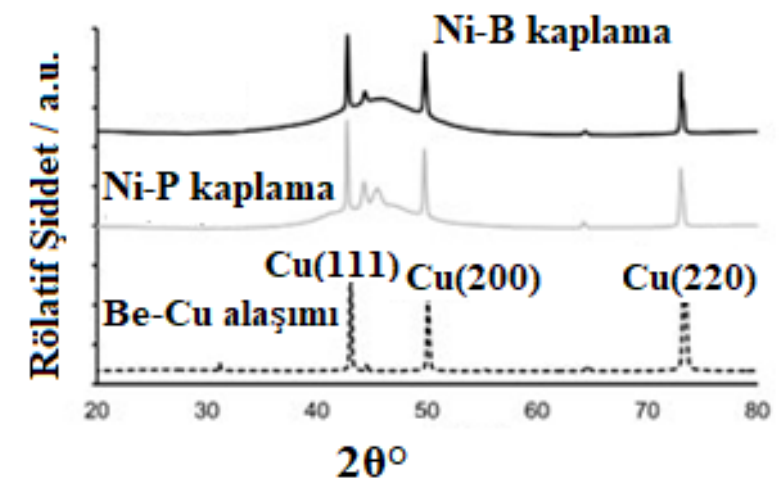

Şekil 3. Be-Cu alaşımı, akımsız $\mathrm{Ni}-\mathrm{P}$ ve $\mathrm{Ni}-\mathrm{B}$ kaplamaların XRD paternleri

$\mathrm{Be}-\mathrm{Cu}$ alaşımı, akımsız Ni-P ve Ni-B kaplamaların sertlikleri sırasıyla $202 \mathrm{HV}_{0,01}, 460 \mathrm{HV}_{0,01}$ ve $760 \mathrm{HV}_{0,01}$ olarak ölçülmüştür. Bu çalışmadan elde edilen mikrosertlik sonuçları daha önce farklı alaşımlar üzerine yapılan akımsız Ni-P ve Ni-B kaplamaların mikrosertlik sonuçları ile uyumlu olduğu belirlenmiştir. Örneğin Zhang vd. [9], AZ91D Mg alaşımı üzerine yaptıkları Ni-P kaplamanın $400 \mathrm{HV}_{0,01}$ ve $\mathrm{Ni}$ $\mathrm{B}$ kaplamanın ise $650 \mathrm{HV}_{0,01}$ olarak rapor etmişlerdir. $\mathrm{Ni}-\mathrm{B}$ kaplamanın sertliğindeki artış, nikel matriste bor tarafından arayer katı çözeltinin oluşumuna bağlanabilir [17].

$\mathrm{Be}-\mathrm{Cu}$ alaşımı ve kaplamaların sürtünme katsayıs1kayma mesafe eğrileri Şekil 4'de verilmektedir. Kayma mesafesi ile sürtünme katsayısı grafiği en yüksek salınımla Be-Cu alaşımı sergilemiştir (Şekil4a). Ni-P kaplama her iki yük $(5$ ve $7.5 \mathrm{~N})$ altında yaklaşık ilk $5 \mathrm{~m}$ ' lik mesafede, sürtünme katsayısı önce artıp, ardından azalan kararlı bir davranış sergileyerek benzer sürtünme davranışı göstermiştir (Şekil 4b). En yüksek sertliğe sahip olan Ni-B kaplama $5 \mathrm{~N}$ yük altında $12 \mathrm{~m}$ kayma mesafesinden sonra sürtünme katsayısı aniden azalıp, deneyin sonuna kadar geniş bir salınım göstermiştir (Şekil 4c). Ancak 7.5 N yük altında ise Ni-B kaplama 35 m kayma mesafesinden sonra en düşük salınımlı olacak şekilde sürtünmeye devam etmiştir.
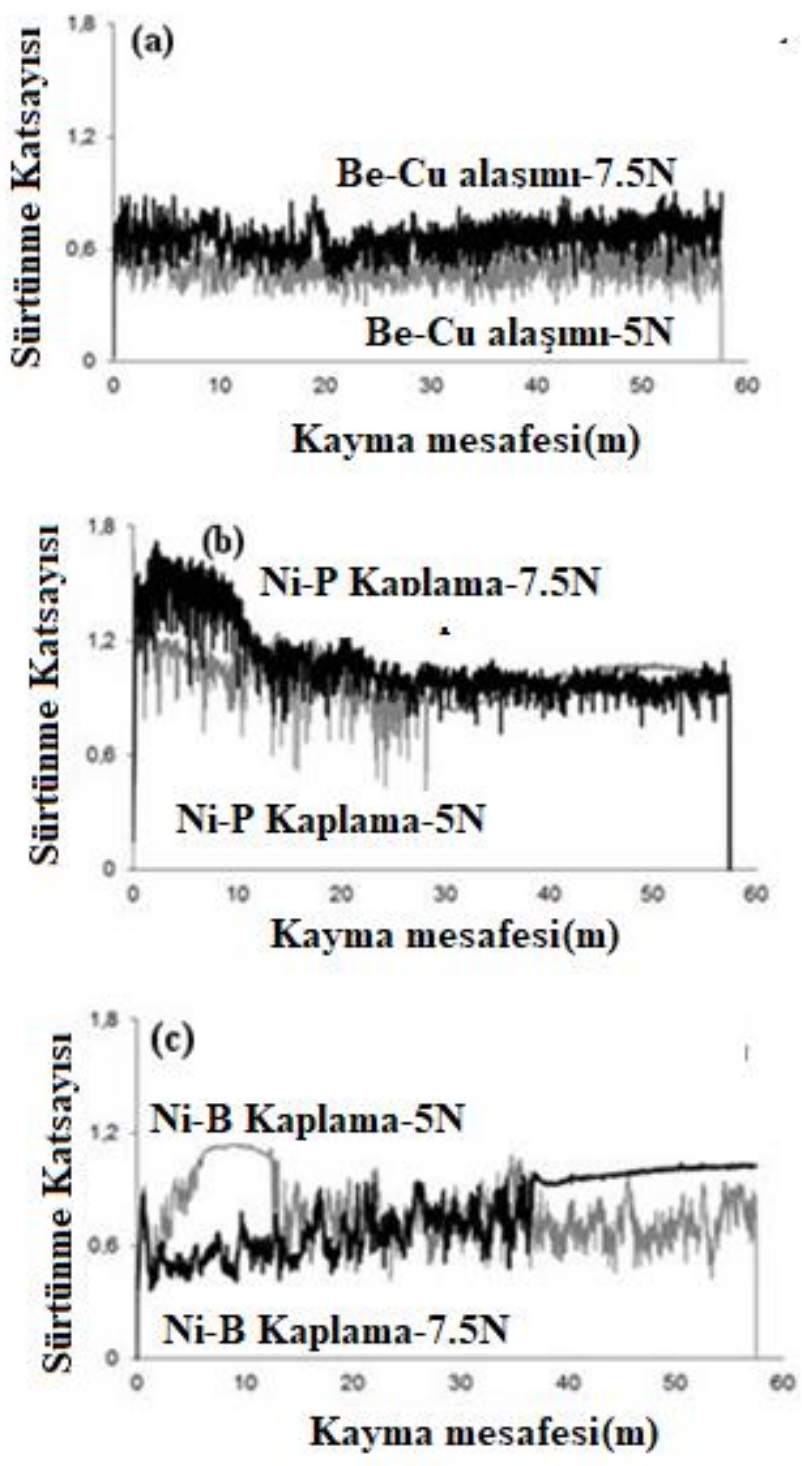

Şekil 4. (a) Be-Cu alaşımı, akımsız (b) Ni-P ve (c) Ni-B kaplamaların kuru ortam sürtünme katsayısı değerlerinin mesafeye bağlı değişimi

Şekil 5 kuru ortam aşınma deneylerinde Be-Cu alaşımı, akımsız Ni-P ve Ni-B kaplamaların aşınma kayıpları verilmektedir. Kuru ortam aşınma koşulları altında her iki yük altında Ni-P kaplamaya kıyasla Ni-B kaplama daha iyi aşınma direnci sergilemektedir. Şekil 6'da aşınma iz genişliği ve mekanik kararlılığı dikkate alındığında, Ni-B kaplama daha küçük aşınma iz genişliği ve daha iyi mekanik kararlılık gösterdiği belirlenmiştir. Daha yüksek büyütmelerde $\mathrm{Be}-\mathrm{Cu}$ alaşımı ile, akımsız Ni-P ve Ni-B kaplamaların farklı aşınma yüzeyi morfolojileri sergiledikleri tespit edilmiştir (Şekil 7). Be-Cu alaşımın kayma yönünde abrasif çizikler içeren geniş aşınma izi gözlenmiştir (Şekil 7). 7.5 N yük altında aşınma sırasında NiP kaplamanın temas yüzeyinde yüksek sürtünme katsayısı (Şekil 4b) ve çatlamalar (Şekil 7) aşınma miktarını artıran en 
önemli etkenler olmuştur. Ancak, Ni-B kaplamanın aşınma izi içerisinde kayma yönünde koyu renkte kaplamanın hala mevcut olduğu gözlenmiştir (Şekil 7). Ni-B kaplamada belirlenen daha yüksek aşınma direnci, bu kaplamanın yüksek sertliğine bağlı olarak daha az plastik deformasyona uğraması ve yağlayıcı özelliği ile açıklanabilir [18].

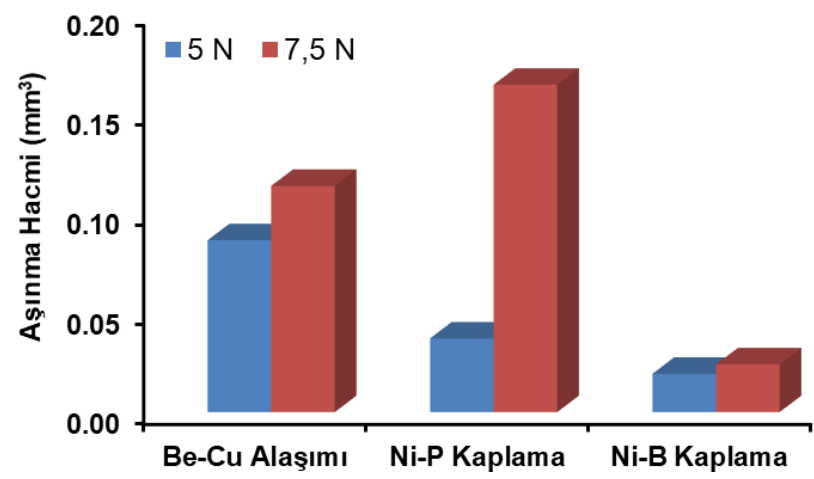

Şekil 5. Kuru ortam aşınma koşulları altında $\mathrm{Be}-\mathrm{Cu}$ alaşımı, akımsız Ni-P ve Ni-B kaplamaların aşınma kayiplar1.

$5 \mathbf{N}$
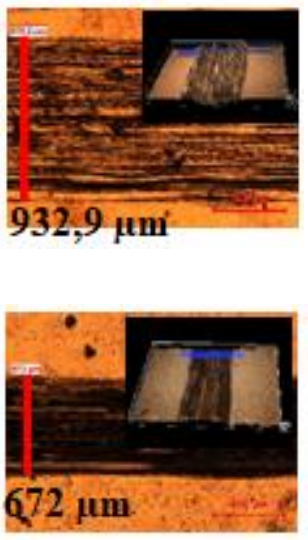

Ni-B
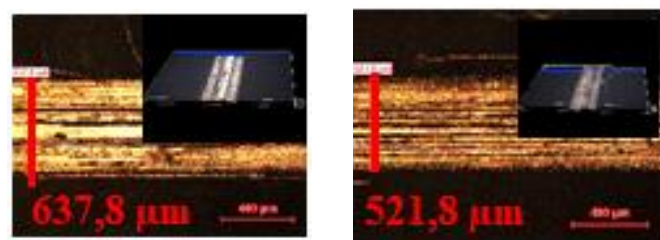

Şekil 6. Be-Cu alaşımı, akımsız Ni-P ve Ni-B kaplamaların aşınma izlerinin düşük büyütme $\mathrm{OM}$ görüntüleri ve 3-D yüzey topografik profilleri

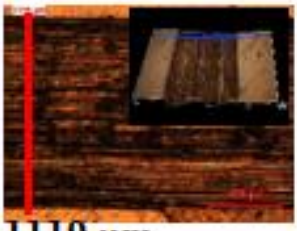

\section{III $9 \mu \mathrm{m}$}

$5 \mathbf{N}$
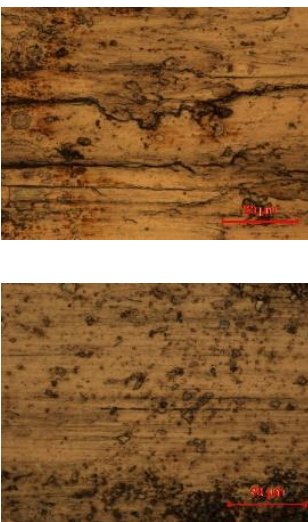

Ni-P

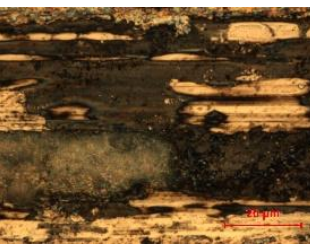

$7.5 \mathrm{~N}$
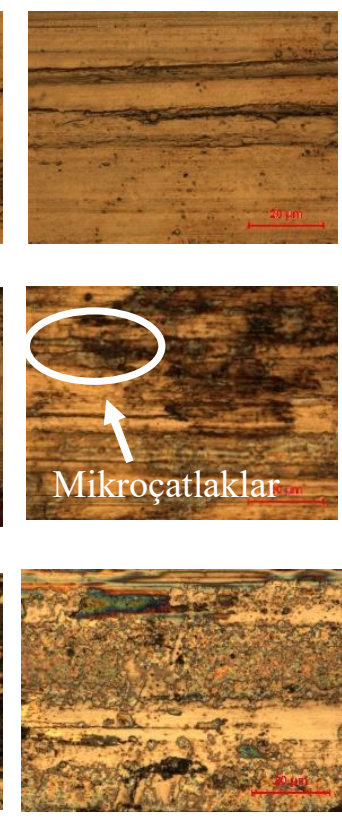

Şekil 7. Be-Cu alaşımı, akımsız Ni-P ve Ni-B kaplamaların aşınma izlerinin yüksek büyütme $\mathrm{OM}$ görüntüleri

$5 \mathbf{N}$

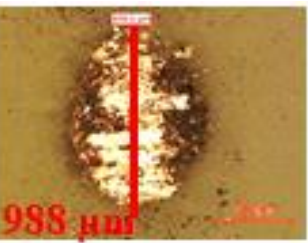

Be-

$\mathrm{Cu}$

Ni-P
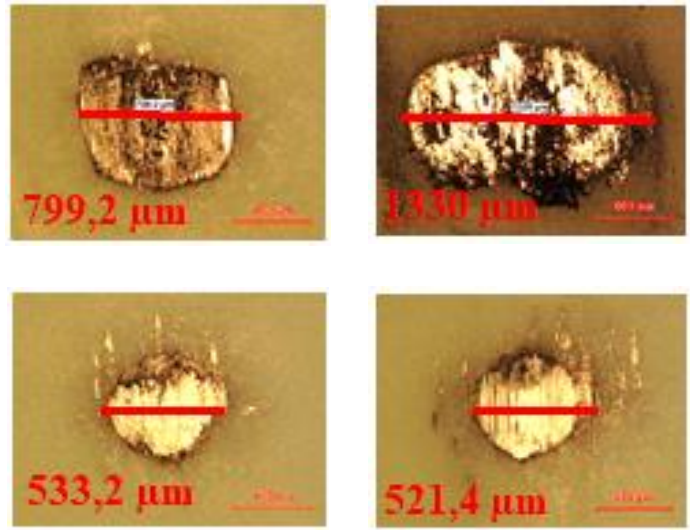

Şekil 8. Be-Cu alaşımı, akımsız Ni-P ve Ni-B kaplamalara temas eden karşı malzemelerin temas yüzey görüntüleri 
Karşı malzeme olarak kullanılan $\mathrm{Al}_{2} \mathrm{O}_{3}$ bilyelerin aşınma yüzeyleri Şekil 8'de verilmektedir. Şekil 5'e bakıldığında 5 $\mathrm{N}$ yük altında $\mathrm{Be}-\mathrm{Cu}$ alaşıma nazaran $\mathrm{Ni}-\mathrm{P}$ ve $\mathrm{Ni}-\mathrm{B}$ kaplamalarda azalan aşınma hacmiyle beraber bilyelerin yüzeyindeki aşınma da azalmıştır. Ancak $7.5 \mathrm{~N}$ yük altında $\mathrm{Be}-\mathrm{Cu}$ alaşıma göre Ni-P kaplamadaki aşınma hacmindeki artış ile aşınan $\mathrm{Al}_{2} \mathrm{O}_{3}$ bilye çapının arttığı dolayısıyla bilyenin daha çok aşındığı anlaşılmaktadır.

\section{Sonuçlar}

$\mathrm{Bu}$ çalışmada ticari kalitede $\mathrm{Be}-\mathrm{Cu}$ alaşımı üzerine akımsız Ni-P ve Ni-B kaplamalar oluşturulmuştur. Bu kaplamalarda yapılan mikroyapı incelemeleri, mikrosertlik ölçümleri ve aşınma deneylerinden elde edilen sonuçlar aşağıda özetlenmiştir;

1. Akımsız kaplamaların mikroyapı görüntüleri Ni-P kaplamanın düz, Ni-B kaplamanın ise karnabahar-vari küresel tanelerden oluşan pürüzlü bir yüzey görüntüsü verdiğini göstermiştir. Yüzey pürüzlülük analizi de en pürüzlü yüzeye Ni-B kaplamanın sahip olduğunu destekleyen sonuçlar vermiştir.

2. Aynı sürede yapılan kaplama işlemi ile, Ni-P kaplama yaklaşık $12 \mu \mathrm{m}$, Ni-B kaplama ise yaklaşık 7-8 $\mu \mathrm{m}$ ortalama kaplama kalınlığı değerleri göstermişlerdir.

3. XRD analizi ile, akımsız kaplamaların amorf ve kristal yapıların bir karışımından oluştuğunu, Ni-B kaplamanın Ni-P kaplama ile karşılaştırıldığında, daha amorf bir yap1 sergilediği aynı analiz sonuçlarından tespit edilmiştir.

4. Yapılan mikrosertlik testi sonrasında elde edilen sonuçlar kaplamasız alaşım ile karşılaştırıldığında, akımsız Ni-P kaplamanın 2.2 kat ve Ni-B kaplamanın ise 3.7 kat önemli miktarda sertliği artırdığı sonucunu ortaya çıkarmıştır.

5. Kuru ortam aşınma deneyleri, her iki yük altında Ni-P kaplamaya kıyasla Ni-B kaplamanın, daha küçük aşınma iz genişliği, aşınma hacminde görülen ciddi azalma, aşınma sırasında yağlayıcı özelliğini kaybetmeden sergileyebildiğini gösteren görüntüler ile bu kaplamanın daha iyi mekanik kararlılık gösterdiğini ortaya koymuştur.

\section{Teşekkür}

$\mathrm{Bu}$ çalışma Bilecik Şeyh Edebali Üniversitesi Bilimsel Araştırma Projeleri Birimi tarafından 2021-01.BŞEÜ.01-02 nolu proje kapsamında desteklenmiştir.

\section{Çıkar çatışması}

Yazarlar çıkar çatışması olmadığını beyan etmektedir.

\section{Benzerlik oranı (iThenticate): $\% 15$}

\section{Kaynaklar}

[1] Z.W. Zhong, M.H. Leong, X.D. Liu, The wear rates and performance of three mold insert materials, Materials and Design, 32, 643-648, 2011. https://doi.org/ 10.1016/j.matdes.2010.08.008.

[2] J.C. Avelar-Batista Wilson, S. Banfield, J. Eichler, A. Leyland, A. Matthews, J. Housden, An investigation into the tribological performance of Physical Vapour Deposition (PVD) coatings on high thermal conductivity $\mathrm{Cu}$-alloy substrates and the effect of an intermediate electroless $\mathrm{Ni}-\mathrm{P}$ layer prior to PVD treatment, Thin Solid Films, 520, 2922-2931, 2012. https://doi.org/10.1016/j.tsf.2011.11.034.

[3] B. Podgornik, O. Massler, F. Kafexhiu, M. Sedlacek, Crack density and tribological performance of hardchrome coatings, Tribol. Int., 121, 333-340, 2018. https://doi.org/10.1016/j.triboint.2018.01.055.

[4] H. Mindivan, Corrosion and tribocorrosion behaviour of WC/C coating on beryllium-copper mould alloy, Mater. Today: Proc., 27 (4), 3114-3118, 2020. https://doi.org/10.1016/j.matpr.2020.03.726.

[5] H. Ogihara, T. Katayama, T. Saji, Electroless deposited robust $\mathrm{Ni}-\mathrm{B}$ films coated with trimethylsiloxysilicate exhibit superhydrophobicity, J. Mater. Chem., 21, 14890-14896, 2011. https://doi.org/10.1039/ C1JM12303C

[6] F. Mindivan, AISI 316L paslanmaz çeliğin yüzey özelliklerine akımsız Ni-B, Ni-P/Ni-B ve Ni-B/Ni-P kaplamaların etkisi. Yüksek Lisans Tezi, Bursa Uludağ Üniversitesi Fen Bilimleri Enstitüsü, Türkiye, 2021.

[7] H. Mindivan, Tribocorrosion behavior of electroless Ni-P/Ni-B duplex coating on AA7075 aluminum alloy, Ind. Lubr. Tribol., 71(2), 630-635, 2019. https://doi.org/10.1108/ILT-05-2018-0177

[8] F. Mindivan, H. Mindivan, C. Darcan, Electroless NiB coating of pure titanium surface for enhanced tribocorrosion performance in artificial saliva and antibacterial activity. Tribol. Ind., 39(2), 270-276, 2017.https://doi.org/10.24874/ti.2017.39.02.15

[9] J. Zhang, Z.-H. Xie, H. Chen, C. Hu, L. Li, B. Hu, Z. Song, D. Yan, G. Yu, Electroless deposition and characterization of a double-layered Ni-B/Ni-P coating on AZ91D Mg alloy from eco-friendly fluoride-free baths, Surf. Coat. Technol., 342, 178-189. 2018. https://doi.org/10.1016/j.surfcoat.2018.02.105.

[10] U. Matik, Effect of crystallization on wear and corrosion behavior of electroless $\mathrm{Ni}-\mathrm{P} / \mathrm{Ni}-\mathrm{B}$ duplex coating on ferrous PM compacts, Kov. Mater., 58, 247 254, 2020. https://doi.org/10.4149/km_2020_4_247

[11] R.C. Agarwala, V. Agarwala, Electroless alloy/composite coatings: A review, Sadhana, 28, 475493, 2003. https://link.springer.com/article/10.1007/ BF02706445.

[12] H. Zhang, Y. Jiang, J. Xie, Y. Li, L. Yue, Precipitation behavior, microstructure and properties of aged $\mathrm{Cu}-1.7$ wt\% Be alloy, J. Alloys Compd., 773, 1121-1130, 2019. https://doi.org/10.1016/j.jallcom.2018.09.296.

[13] I. Baskaran, R.S. Kumar, T.S.N. Sankara Narayanan, A. Stephen, Formation of electroless $\mathrm{Ni}-\mathrm{B}$ coatings using low temperature bath and evaluation of their characteristic properties, Surf. Coat. Technol., 200,6888-6894, 2006. https://doi.org/10.1016/ j.surfcoat.2005.10.013.

[14] M. Czagány, P. Baumli, G. Kaptay, The influence of the phosphorous content and heat treatment on the nano-micro-structure, thickness and micro-hardness of electroless Ni-P coatings on steel, Appl. Surf. Sci., 
423:160-169, 2017. https://doi.org/10.1016/ j.apsusc.2017.06.168.

[15] K. Krishnaveni, T.S.N. Narayanan Sankara, S.K. Seshadri, Electroless Ni-B coatings: preparation and evaluation of hardness and wear resistance, Surf. Coat. Technol., 190, 115-121. 2005. https://doi.org/ 10.1016/j.surfcoat.2004.01.038.

[16] F. Madah, C. Dehghanian, A.A. Amadeh, (). Investigations on the wear mechanisms of electroless $\mathrm{Ni}-\mathrm{B}$ coating during dry sliding and endurance life of the worn Surfaces, Surf. Coat. Technol., 282:6-15, 2015. https://doi.org/10.1016/j.surfcoat.2015.09.003.

[17] F. Mindivan, H. Mindivan, The study of electroless NiP/Ni-B duplex coating on HVOF-sprayed martensitic stainless steel coating, Acta Phys. Pol., 131 (1), 64-67, 2017.https://doi.org/10.12693/APhysPolA.131.64

[18] H. Mindivan, Tribocorrosion behavior of electroless Ni-P/Ni-B duplex coating on AA7075 aluminum alloy, Ind. Lubr. Tribol., 71 (5), 630-635, 2019. https://doi.org/10.1108/ILT-05-2018-0177. 